\title{
The Wheelchair Circuit: Reliability of a Test to Assess Mobility in Persons With Spinal Cord Injuries
}

\author{
Olga J. Kilkens, MSc, Marcel W. Post, PhD, Lucas H. van der Woude, PhD, Annet J. Dallmeijer, PhD, \\ Wim J. van den Heuvel, PhD
}

ABSTRACT. Kilkens OJ, Post MW, van der Woude LH, Dallmeijer AJ, van den Heuvel WJ. The wheelchair circuit: reliability of a test to assess mobility in persons with spinal cord injuries. Arch Phys Med Rehabil 2002;83:1783-8.

Objective: To assess the reliability of a 9-task wheelchair circuit.

Design: Three test trials per subject were conducted by 2 raters. Inter- and intrarater reliability were examined.

Setting: Eight rehabilitation centers in the Netherlands.

Participants: Convenience sample of 27 patients (age, $\geq 18 y$ ) with spinal cord injury (SCI), all of whom were in the final stage of their inpatient rehabilitation.

Intervention: A wheelchair circuit was developed to assess mobility in subjects with SCI. The circuit consisted of 9 tasks: figure-of-8 shape, doorstep crossing, mounting a platform, sprint, walking, driving up treadmill slopes of $3 \%$ and $6 \%$, wheelchair driving and transfer.

Main Outcome Measures: Task feasibility, task performance time, and peak heart rates.

Results: The number of tasks that subjects could perform varied from 3 to 9 . Feasibility intrarater reliability was .98, and the interrater reliability intraclass correlation coefficient (ICC) was .97. Performance time ICCs ranged from .70 to .99 (mean, .88 ) for intrarater reliability and from .76 to .98 (mean, .92) for interrater reliability. Heart rate ICCs ranged from .64 to .96 (mean, .81) for intrarater reliability and from .82 to .99 (mean, .89) for interrater reliability.

Conclusions: The reliability of the wheelchair circuit was good. More research is needed to assess test validity and responsiveness.

Key Words: Rehabilitation; Reliability and validity; Spinal cord injuries; Wheelchairs.

(C) 2002 by the American Congress of Rehabilitation Medicine and the American Academy of Physical Medicine and Rehabilitation

B ECAUSE APPROXIMATELY 82\% OF persons with a spinal cord injury (SCI) are dependent on wheelchairs for mobility, ${ }^{1}$ wheelchairs are important in achieving independent mobility. Wheelchair propulsion is an inefficient and strenuous method of locomotion. ${ }^{2}$ As a result of a reduction in active

From the iRv, Institute for Rehabilitation Research, Hoensbroek (Kilkens, Post, van den Heuvel); and Faculty of Human Movement Sciences, Vrije University, Amsterdam (van der Woude, Dallmeijer), the Netherlands.

Supported by the Health Research and Development Council of the Netherlands (grant no. 1435.0003).

Presented as a poster at the 1 st World Congress of the International Society of Physical and Rehabilitation Medicine, July 2001, Amsterdam.

No commercial party having a direct financial interest in the results of the research supporting this article has or will confer a benefit upon the author(s) or upon any organization with which the author(s) is/are associated.

Correspondence to Olga Kilkens, MSc, Institute for Rehabilitation Research, PO Box 192, 6430 AD Hoensbroek, The Netherlands, e-mail: olga.kilkens@irv.nl. Reprints are not available.

0003-9993/02/8312-6908\$35.00/0

doi:10.1053/apmr.2002.36066 muscle mass, the physical capacity of persons with SCI is often very low. This leads to high physical strain during wheelchair performance. ${ }^{3}$ A thorough mastery of wheelchair skills, combined with an optimal physical capacity, can enhance mobility. Increasing physical capacity and specific wheelchair skills therefore are important goals of rehabilitation after SCI. ${ }^{4}$

For this study, mobility was defined as the process of moving oneself and of changing and maintaining postures. ${ }^{5}$ The most common way to assess the mobility of persons with SCI is through observation. The FIM ${ }^{\mathrm{TM}}$ instrument and the Modified Barthel Index are 2 frequently used observational measurement instruments. ${ }^{6,7}$ Currently, the FIM is the most widely accepted and most commonly used measure to evaluate the mobility of persons with SCI. ${ }^{8}$ However, these observational methods have some disadvantages. First, they are not sensitive enough to detect small changes in mobility ${ }^{9-13}$ because they only record whether a person can perform a particular task or whether the task is performed independently. Small improvements in the quality of the task performance can often not be scored. Nonetheless, these small changes can be of great importance. Second, these methods do not provide information about the physical strain involved in performing a particular task.

To skirt these disadvantages, several researchers $9,10,14-20$ have used functional tests, including the performance of wheelchair tasks, to assess mobility gain or physical strain during wheelchair tasks. Cardus et $\mathrm{al}^{20}$ designed an open-air test circuit. In such a situation, standardization of environmental parameters is not possible, which limits the reliability of this circuit as a measurement instrument. Harvey et al ${ }^{10}$ used 6 functional tasks to assess mobility in wheelchair-dependent paraplegic subjects. Tasks used were supine to long sitting, horizontal and vertical transfer, wheelchair propulsion on a flat surface, driving up a ramp, and negotiating curbs. A 6-point scoring system was used that considered only the level of assistance needed during task performance. Performance time and physical strain were not assessed, which makes this test less suitable for detecting small changes in mobility. In the Netherlands, Michels et $\mathrm{al}^{16}$ and Meijs et al ${ }^{19}$ developed a wheelchair circuit with 6 tasks. Each task was performed for 3 minutes to reach a steady-state condition. However, this circuit proved highly impractical for use in different rehabilitation centers. Both Janssen et $\mathrm{al}^{15}$ and Dallmeijer et $\mathrm{al}^{14}$ used several diverse functional activity of daily living (ADL) tasks to assess physical strain during task performance. Some tasks specifically referred to mobility, such as ascending a ramp and transferring from a wheelchair to a toilet. Other tasks were related to other ADLs, such as changing sheets, preparing lunch, and washing hands. Until now, there has been no uniformly sensitive measurement instrument with which to assess functional wheelchair skills.

An ongoing longitudinal, multicenter prospective cohort study was initiated in 1999 in The Netherlands in which people with acute SCI are followed during and after clinical rehabilitation. Within the scope of this study, a functional test-the wheelchair circuit-was developed. Its purpose is to assess 
mobility during and after clinical rehabilitation. The wheelchair test is primarily designed for research purposes but may also be used in a clinical setting. The reliability of any new measurement instrument is important to ensure that the measurement error is small enough to detect actual changes in what is being measured. ${ }^{21}$ The aim of this study was to assess the feasibility and the inter- and intrarater reliability of this wheelchair circuit.

\section{METHODS}

\section{Participants}

Twenty-seven wheelchair users with SCI (convenience sample) were recruited from among patients admitted to any 1 of 8 rehabilitation centers that specialize in SCI rehabilitation in The Netherlands. All subjects were in the final stage of their clinical rehabilitation program, used a hand-rim wheelchair, and were between 18 and 65 years of age. Potential participants were not included if they had a current cardiorespiratory disorder or orthopedic or other medical complications that restricted them in performing the tasks required for the wheelchair circuit. Subject characteristics are summarized in table 1.

All subjects completed a consent form after they were given information about the testing procedures. All tests and protocols were approved by the Medical Ethics Committee of the Stichting Revalidatie Limburg and Kenniscentrum voor Revalidatie en Handicap.

\section{Testing Procedure}

The study involved 3 performance trials of the wheelchair circuit. To minimize a learning effect, a practice session was performed before the test trials. Eleven research assistants conducted the tests; 8 worked in the 8 participating rehabilitation centers ( 6 physical therapists, 1 occupational therapist, 1 qualified nurse), and 3 were students in human movement sciences. All 8 research assistants received extensive training in how to administer the tests.

Subjects were tested in the rehabilitation centers in which they were inpatients. The practice session was supervised by the research assistant working in that center (internal research assistants). Two test trials were directed by the internal research assistant and the third by an external research assistant (fig 1). The sequential order of the trials supervised by the internal or external research assistant was varied arbitrarily.

During all test trials, heart rate was monitored with a Polar Sport Tester. ${ }^{\text {a }}$ Performance time was measured with a stopwatch, and task feasibility (the ability to perform the tasks as required-yes or no) was subjectively assessed by the research assistants.

Time between each trial was at least 1 day and not more than 3 days. The whole testing period per subject thus ranged from 8 to 13 days. Subjects performed the test trials at the same time of the day. To avoid influencing the test results, subjects were

Table 1: Subject Characteristics

\begin{tabular}{llccr}
\hline $\begin{array}{c}\text { Type of } \\
\text { Injury }\end{array}$ & $\begin{array}{c}\text { Completeness } \\
\text { of Injury }\end{array}$ & $\mathrm{n}$ & $\begin{array}{c}\text { Mean Age } \pm \mathrm{SD} \\
(\mathrm{y})\end{array}$ & $\mathrm{M} / \mathrm{F}$ \\
\hline Paraplegia & Complete & 9 & $39.7 \pm 11.5$ & $5 / 4$ \\
Paraplegia & Incomplete & 5 & $29.8 \pm 8.2$ & $3 / 2$ \\
Tetraplegia & Complete & 5 & $25.4 \pm 4.8$ & $4 / 1$ \\
Tetraplegia & Incomplete & 8 & $37.9 \pm 15.9$ & $6 / 2$ \\
Total N & & 27 & $34.7 \pm 12.5$ & $18 / 9$ \\
\hline
\end{tabular}

Abbreviations: SD, standard deviation; $M$, male; $F$, female.

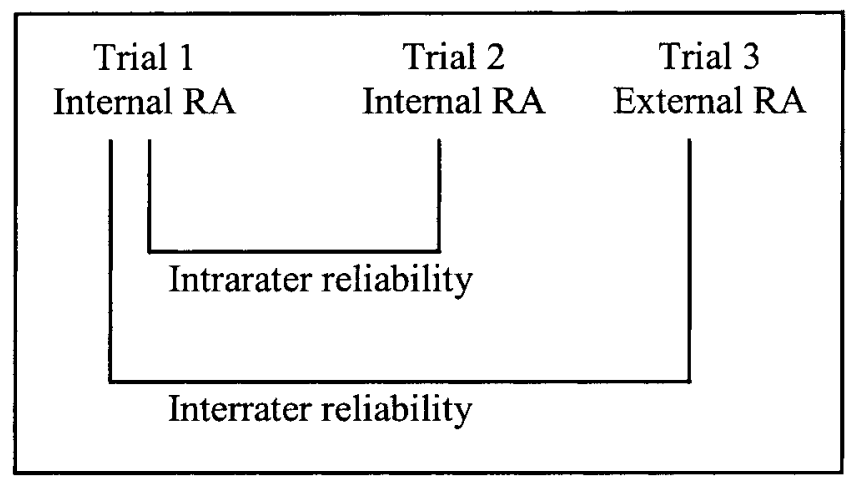

Fig 1. Assessment of intra- and interrater reliability. Abbreviation: $R A$, research assistant.

asked to refrain from smoking and drinking alcohol and coffee for at least 2 hours before each trial. They were also asked to void just before testing.

Not all subjects performed all 3 test trials. Because of a scheduling problem, 1 subject did not perform the test trial conducted by an external research assistant. A second subject received another wheelchair after he had completed the first trial (conducted by the internal research assistant). That trial was not included in the statistical analyses. Because of pressure ulcers, a third subject was unable to perform the last 2 test trials, and in 1 subject, the heart rate-monitoring devices failed during the third test trial with an external research assistant because of transmitter displacement.

\section{The Wheelchair Circuit}

The wheelchair circuit consisted of 9 standardized tasks related to ADLs; they were all conditional to mobility in persons with an SCI. The tasks used in the circuit were adapted from the mobility-related tasks used by Dallmeijer et al, ${ }^{14}$ Janssen et al, ${ }^{15}$ and Harvey et al. ${ }^{10}$ Because the tasks vary in difficulty, the circuit can be used to assess the mobility of persons with different competency levels.

The 9 tasks of the wheelchair circuit are described as follows.

Figure-of-8 shape. Three markers were placed in a straight line, $1.5 \mathrm{~m}$ apart. Subjects started at the first marker and drove the wheelchair in a figure-of- 8 shape around the other 2 markers. Time was recorded from the moment the subjects began to drive until the front wheels of the wheelchair passed the first marker again. Maximum time allotted to perform this task was 1 minute.

Crossing a doorstep. A wooden doorstep, .04m high, $.15 \mathrm{~m}$ wide, and $1.20 \mathrm{~m}$ long, was placed in a doorway. A marker $1 \mathrm{~m}$ in front of and $1 \mathrm{~m}$ behind the doorstep was placed on the floor. Subjects started at the first marker and crossed the doorstep. Time was recorded from the moment subjects started to drive until the front wheels passed the marker on the other side of the doorstep. Subjects were allowed to make several attempts within a maximum of 2 minutes. In doing so, the maximum run-up allowed was the $1 \mathrm{~m}$ indicated by the marker on the floor.

Mounting a platform. A wooden platform, $0.10 \mathrm{~m}$ high, $1.20 \mathrm{~m}$ wide, and $1.20 \mathrm{~m}$ long, was placed against a wall. Two meters before the platform, a marker was placed on the floor. Subjects started at this marker and drove up onto the platform. Time was recorded from the moment the subjects started to drive until all 4 wheels were on the platform. Subjects were 
Table 2: Performance Time of the Different Tasks of the Wheelchair Circuit for the 3 Test Trials

\begin{tabular}{lrcccccc}
\hline & \multicolumn{3}{c}{ Intrarater } & & \multicolumn{3}{c}{ Interrater } \\
\cline { 2 - 5 } \multicolumn{1}{c}{ Task } & $\mathrm{n}$ & Trial 1 & Trial 2 & & $\mathrm{n}$ & Trial 1 & Trial 3 \\
\hline Figure-of-8 shape & 25 & $16.3 \pm 8.6$ & $15.6 \pm 8.1$ & & 25 & $16.1 \pm 8.7$ & $16.3 \pm 9.6$ \\
Crossing doorstep & 16 & $4.7 \pm 4.1$ & $4.8 \pm 3.6$ & & 17 & $5.2 \pm 4.7$ & $6.4 \pm 7.5$ \\
Mounting platform & 8 & $7.1 \pm 4.8$ & $6.6 \pm 9.5$ & 8 & $11.6 \pm 12.4$ & $12.3 \pm 14.1$ \\
Sprint & 25 & $11.7 \pm 5.5$ & $11.5 \pm 6.0$ & 25 & $11.6 \pm 5.6$ & $11.4 \pm 6.0$ \\
Transfer & 19 & $47.4 \pm 49.8$ & $42.2 \pm 38.3$ & & 18 & $35.9 \pm 34.7$ & $42.4 \pm 45.7$ \\
\hline
\end{tabular}

NOTE. Values are $\mathrm{n}$ and mean $\pm \mathrm{SD}$.

allowed to make several attempts within a maximum time of 2 minutes. In doing so, the maximum run-up allowed was the $2 \mathrm{~m}$, as indicated by the marker on the floor. This task was not considered to have been completed if a subject did not succeed in crossing the doorstep.

Sprint. Two markers were placed on the floor, $15 \mathrm{~m}$ apart. Subjects started at the first marker and drove as fast as possible to the second marker. Time was recorded from the moment subjects started to drive until the front wheels passed the second marker. Maximum time to perform this task was 1 minute.

Walking. Two markers were placed on the floor, $15 \mathrm{~m}$ apart. Subjects who were able to ambulate walked up and down between these markers for 2 minutes, from a standing start. They were permitted to use the walking aids they normally used when walking. Subjects were asked to walk at their own personal and safe pace. If they were unable to walk for 2 minutes, the time recorded was that from the moment they started walking until they stopped. The distance covered was measured and rounded off to the nearest meter. At all times, the research assistant walked alongside the subject to help prevent a fall.

Note that walking is a task that does not seem to fit into a wheelchair circuit. It is, however, an important aspect of mobility for people with incomplete lesions who are able to walk. We decided, therefore, to include this task in the wheelchair circuit.

3\% slope. This task was performed while driving on a treadmill. ${ }^{\text {b }}$ The treadmill started with the speed set at $.56 \mathrm{~m} / \mathrm{s}$. After 10 seconds, the slope was raised to $3 \%$ (which took 12s), and after this inclination was reached, the subjects had to keep driving for 10 seconds before the incline was returned to $0 \%$ (which also took 12s). The test stopped when the treadmill reached the horizontal position again. Performance time of this test was constant.

6\% slope. This task was the same as the 3\% slope, except that the slope was increased to $6 \%$. Increasing the slope to $6 \%$ took 23 seconds, as did decreasing the slope back to $0 \%$. This task was not attempted if the subject did not succeed in performing the $3 \%$ slope task. Performance time of this test was constant.

Wheelchair driving. The subjects drove for 5 minutes on a treadmill, at a speed of $.83 \mathrm{~m} / \mathrm{s}$.

Transfer. A line was placed on the floor $1 \mathrm{~m}$ from a treatment table and parallel to it. Subjects were asked to transfer from the wheelchair to the table, beginning from the line. First, they had to drive up to the table and put the wheelchair in position to make a transfer. Then, they transferred from the wheelchair to the table, with their legs hanging over the edge and finally they lifted them onto the table while remaining seated. The table was set at the same height as the top of the seat cushion in the wheelchair. This task was not attempted if a subject had a score lower than 3 on the FIM item transfer bed/chair/wheelchair. ${ }^{8}$ The research assistants could not lift any part of the subject's body to help them to perform the task. The subjects were allowed to use the assistive device(s) they normally used in performing a transfer. Time was recorded from the moment subjects started to move until they were sitting with their legs on the bed. Maximum time to perform this task was 5 minutes.

All tasks were performed in the sequence described earlier on a hard and smooth floor surface. The subjects performed the tasks in their own wheelchairs. During each task, task feasibility, performance time, and peak heart rate were recorded. Immediately after each task, subjects sat quietly in their wheelchairs for 2 minutes as their heart rates returned to resting levels.

The 9 tasks described previously relate mainly to 3 different aspects of mobility: tempo, technical skills, and physical capacity. The figure-of- 8 shape and the sprint mainly focus on tempo. Crossing a doorstep, mounting a platform, and making a transfer are tasks that require the highest level of technical skills; the tasks of wheelchair driving, ascending slopes, and walking mostly reflect a subject's physical capacity. This segmentation between the tasks is, of course, not as strict as stated earlier. Walking, for instance, also reflects technique and tempo. Ascending a slope requires technique. It is, however, clear that the different tasks of the wheelchair circuit represent the different aspects of wheelchair mobility.

\section{Statistical Analysis}

Intrarater reliability was assessed by using trials 1 and 2 , both of which were conducted by the internal research assistant. For the assessment of the interrater reliability, trial 1 and trial 3 (with external research assistant) were used (fig 1). The intraclass correlation coefficient (ICC) was used as a measure of reliability. For both the inter- and intrarater reliability, a 1-way random effects model was applied.22 A priori, an ICC of .80 or higher was defined as an indication of good reliability.

To calculate the intra- and interrater reliability of the feasibility of the different tasks, we used the sum of the number of tasks that each subject was able to perform.

\section{RESULTS}

Because of various task difficulties, not all subjects were able to perform all 9 tasks of the wheelchair circuit. This, in combination with the missing trials reported in the Methods section, resulted in a variation in the number of subjects for whom heart rate and/or performance times were available.

Tables 2 and 3 display, respectively, performance times and peak heart rates recorded during the performance on the different tasks. The walking, 3\%- and 6\%-slope, and wheelchairdriving tasks had a fixed duration and are therefore not shown in table 2. Figure 1 shows that trial 1 was used for the assessment of both inter- and intrarater reliability. For the intrarater reliability, only subjects who had a complete data set for trials 
Table 3: Peak Heart Rates During the Different Tasks of the Wheelchair Circuit for the 3 Test Trials

\begin{tabular}{|c|c|c|c|c|c|c|}
\hline \multirow[b]{2}{*}{ Task } & \multicolumn{3}{|c|}{ Intrarater } & \multicolumn{3}{|c|}{ Interrater } \\
\hline & $\mathrm{n}$ & Trial 1 & Trial 2 & $\mathrm{n}$ & Trial 1 & Trial 3 \\
\hline Figure-of-8 shape & 24 & $107.4 \pm 17.6$ & $103.8 \pm 17.2$ & 23 & $110.2 \pm 16.2$ & $107.1 \pm 15.7$ \\
\hline Crossing doorstep & 16 & $100.5 \pm 20.2$ & $95.9 \pm 18.7$ & 16 & $104.9 \pm 16.9$ & $106.1 \pm 16.8$ \\
\hline Mounting platform & 8 & $114.3 \pm 19.2$ & $106.3 \pm 18.8$ & 8 & $113.8 \pm 18.7$ & $107.9 \pm 27.1$ \\
\hline Sprint & 25 & $107.5 \pm 18.3$ & $107.2 \pm 15.8$ & 24 & $109.8 \pm 16.9$ & $109.2 \pm 16.6$ \\
\hline Walking & 8 & $130.4 \pm 22.0$ & $131.5 \pm 23.9$ & 8 & $130.4 \pm 22.0$ & $132.4 \pm 22.9$ \\
\hline $3 \%$ slope & 20 & $99.4 \pm 16.4$ & $94.7 \pm 15.6$ & 19 & $102.1 \pm 14.8$ & $99.1 \pm 13.0$ \\
\hline $6 \%$ slope & 15 & $108.3 \pm 17.2$ & $103.9 \pm 17.6$ & 14 & $111.7 \pm 15.1$ & $111.8 \pm 15.6$ \\
\hline Wheelchair driving & 21 & $103.1 \pm 17.3$ & $99.7 \pm 16.5$ & 21 & $105.1 \pm 14.5$ & $105.9 \pm 13.3$ \\
\hline Transfer & 18 & $112.7 \pm 16.4$ & $106.1 \pm 13.4$ & 17 & $115.7 \pm 17.0$ & $114.7 \pm 17.7$ \\
\hline
\end{tabular}

NOTE. Values are $\mathrm{n}$ or mean $\pm \mathrm{SD}$.

1 and 2 were included, whereas the assessment of the interrater reliability required a complete data set for trials 1 and 3 . As a result, the group composition of subjects in trial 1 differs slightly for the intra- and the interrater reliability.

\section{Task Feasibility}

The results of trial 1 were used to describe task feasibility. The number of tasks that each subject was able to perform varied from $3(n=2)$ to $9(n=3)$. The remaining subjects completed $8(n=7), 7(n=4), 6(n=4), 5(n=4)$, or $4(n=3)$ tasks.

Figure 2 shows the number of subjects who were able to perform the different tasks. All 27 subjects were able to perform the figure-of- 8 shape and sprint tasks, whereas only 8 subjects were able to walk for 2 minutes.

Note that the number of subjects shown in figure 2 does not always correspond to the available data in tables 2 through 4 because of missing data attributable to measurement failure.

\section{Inter- and Intrarater Reliability}

The ICC of the intrarater reliability of the sum of tasks that each subject was able to perform was $.98(n=25 ; 95 \%$ confidence interval $[\mathrm{CI}], .96-.99)$. The interrater reliability showed an ICC of $.97(n=25,95 \%$ CI, .94-.99).

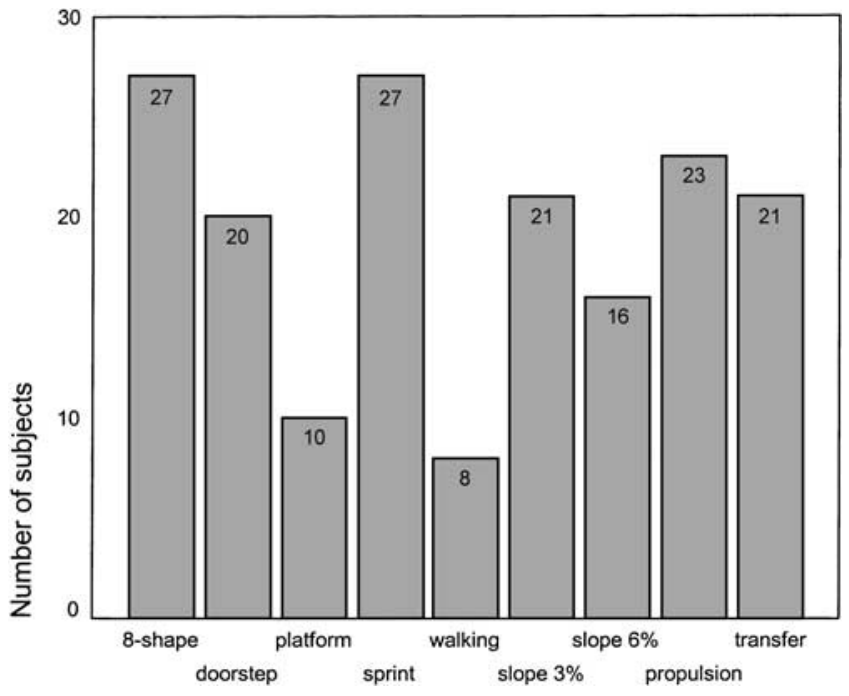

Fig 2. Number of subjects who were able to perform the different tasks (trial 1).
The inter- and intrarater reliability results of task performance time are shown in table 4 . Because of the fixed duration of the walking, the 3\%- and 6\%-slope, and the 5-minute wheelchair-driving tasks, they are not presented here. For the figureof- 8 shape, sprint, and transfer, both inter- and intrarater reliability were high, with ICCs ranging from .94 to .99 . The interrater reliability of mounting the platform was good, with an ICC of .96 , whereas the intrarater reliability was slightly below threshold, with an ICC of .78. Both inter- and intrarater reliability for crossing the doorstep were below the desired value of .80 (ICC $=.76, .71$, respectively).

Table 5 shows the inter- and intrarater reliability results of the recorded peak heart rate during the different tasks. Intrarater reliability was good for the figure-of- 8 shape, crossing doorstep, mounting platform, sprint, walking, slope $6 \%$, and wheelchair driving (ICC range, .83-.96). The 3\% slope and transfer showed lower ICCs ( $\mathrm{ICC}=.69, .68$, respectively). All tasks showed high interrater reliability with ICCs, ranging from .82 to .99 .

\section{DISCUSSION}

This study examined the inter- and intrarater reliability of a wheelchair circuit designed to assess the mobility of persons with SCI. This study included only subjects in their last stage of clinical rehabilitation. This was done to avoid learning and training effects during the testing period, which might have negatively influenced reliability. There was no indication that the reliability results were not representative for persons with SCI in earlier phases of clinical rehabilitation or who were living at home after rehabilitation.

Results showed that not all subjects could perform all tasks; therefore, some ICC values were based on a small number of subjects. This must be considered when interpreting the reported ICC values.

Table 4: Intra- and Interrater Reliability of the Time Needed to Perform the Different Tasks of the Wheelchair Circuit

\begin{tabular}{|c|c|c|c|c|c|c|}
\hline \multirow[b]{2}{*}{ Task } & \multicolumn{3}{|c|}{ Intrarater Reliability } & \multicolumn{3}{|c|}{ Interrater Reliability } \\
\hline & $\mathrm{n}$ & ICC & $95 \% \mathrm{Cl}$ & $\mathrm{n}$ & ICC & $95 \% \mathrm{Cl}$ \\
\hline Figure-of-8 shape & 25 & .97 & $.94-.99$ & 25 & .97 & $.93-.99$ \\
\hline Crossing doorstep & 16 & .71 & $.19-.90$ & 17 & .76 & $.36-.91$ \\
\hline Mounting platform & 8 & .78 & $.00-.96$ & 8 & .96 & $.82-.99$ \\
\hline Sprint & 25 & .99 & $.97-.99$ & 25 & .98 & $.96-.99$ \\
\hline Transfer & 19 & .94 & $.84-.98$ & 18 & .95 & $.87-.98$ \\
\hline
\end{tabular}


Table 5: Intra- and Interrater Reliability of the Maximum Heart Rates Recorded During the Different Tasks of the Wheelchair Circuit

\begin{tabular}{|c|c|c|c|c|c|c|}
\hline \multirow[b]{2}{*}{ Heart Rate Variables } & \multicolumn{3}{|c|}{ Intrarater } & \multicolumn{3}{|c|}{ Interrater } \\
\hline & $\mathrm{n}$ & ICC & $95 \% \mathrm{Cl}$ & $\mathrm{n}$ & ICC & $95 \% \mathrm{Cl}$ \\
\hline Figure-of-8 shape & 24 & .85 & $.67-$ & 23 & .87 & $.69-.94$ \\
\hline Crossing doors & 16 & .90 & $.74-$ & 16 & .93 & $.81-.98$ \\
\hline Mounting platform & 8 & .84 & $.27-.97$ & 8 & .83 & $.22-.97$ \\
\hline Sprint & 25 & .83 & $.61-.92$ & 24 & .82 & $.58-.92$ \\
\hline Walking & 8 & .96 & $.84-.99$ & 8 & .99 & $.93-1.00$ \\
\hline Slope $3 \%$ & 20 & .69 & $.24-.88$ & 19 & .82 & $.54-.93$ \\
\hline Slope 6\% & 15 & .85 & $.57-.95$ & 14 & .91 & $.72-.97$ \\
\hline Wheelchair driving & 21 & .84 & $.62-.94$ & 21 & .88 & $.71-.95$ \\
\hline Transfer & 18 & .68 & $.16-.88$ & 17 & .97 & $.92-.99$ \\
\hline
\end{tabular}

\section{Feasibility}

To enhance test sensitivity, the tasks each had different difficulty levels. The fact that the number of feasible tasks varied between subjects confirms that the tasks were not equally difficult to perform. Mounting a platform and walking were the most difficult tasks to perform. The easiest tasks were the 8-shape and the sprint, which all subjects performed. Most subjects $(n=22)$ were able to complete 5 or more tasks, indicating that the difficulty level was not set too high. The fact that the ability to perform tasks varied between subjects suggests that the wheelchair circuit has a discrimination validity.

\section{Inter- and Intrarater Reliability}

Overall, the inter- and intrarater reliability of the wheelchair circuit was satisfactory. The doorstep-crossing task showed an inter- and intrarater reliability of the performance time just below threshold. The intrarater reliability of the performance time of mounting a platform also was just below threshold. The reason for these lower ICC values may be that performance time on these tasks is more dependent on coincidence. Any failed attempt (eg, because of a miss hit of the hand rims) costs many seconds and may thus result in large differences between trials. Because of this, performance time is not an adequate outcome measure in these 2 tasks and will not be considered in future tests.

Our results show that peak heart rates can be reliably measured during the performance of the different tasks of the wheelchair circuit. This was also found by Janssen et al, ${ }^{23}$ Nijhoff et al, ${ }^{17}$ and Bhambhani et al, ${ }^{24}$ who stated that heart rate responses can be reliably recorded in persons with SCI, even in non-steady-state conditions. The intrarater reliability of the heart rates was high in all tasks, except the $3 \%$ slope and the transfer. These 2 tasks showed ICCs below the cutoff point of .80 , a fact that we cannot explain.

To assess whether the circuit is sensitive to changes in mobility, further longitudinal research is needed in which subjects take the test at different times during clinical rehabilitation. Studies to date look promising because Janssen et al ${ }^{15,25}$ has shown that there is a relation between physical strain during standardized ADL tasks and physical capacity in men many years after SCI.

The wheelchair circuit was primarily designed to be used in a longitudinal study design to assess changes in mobility during and after rehabilitation. In cross-sectional study designs, it can be useful to chart the mobility of wheelchair-dependent persons with SCI. At this point, the different tasks of the wheelchair circuit are scored and reviewed separately, resulting in 3 different scores per task.
In the current validation of the circuit, the aim is to design a scoring system that reflects a person's wheelchair mobility in a comprehensible way. Depending on the data, this may result in 1 score per task that combines feasibility, performance time, and physical strain during task performance, or it may result in 1 total score for the test as a whole.

\section{CONCLUSION}

The overall reliability of the wheelchair circuit was good. Performance time of the crossing doorstep and mounting platform tasks were not reliable and therefore cannot be considered determinants of mobility. The wheelchair circuit seems to be an adequate instrument with which to assess mobility in persons with SCI; however, more research is needed to assess its responsiveness and validity.

Acknowledgments: Participating rehabilitation centers included Revalidatiecentrum Hoensbroek, Revalidatiecentrum Amsterdam, Heliomare Wijk aan Zee, Beatrixoord Haren, De Hoogstraat Utrecht, Het Roessingh Enschede, Rijndam Rotterdam, and Sint Maartenskliniek Nijmegen. We thank research assistants Jos Bloemen, Suzanne Ewalds, Sacha van Langeveld, Femke van der Linden, Peter Luthart, Karin Postma, Hennie Rijken, Marijke Schuitemaker, Ilse Swinkels, Linda Valent, and Ferry Woldring for their participation in data collection.

\section{References}

1. Post MW, van Asbeck FW, van Dijk AJ, Schrijvers AJ. Services for spinal cord injured: availability and satisfaction. Spinal Cord 1997;35:109-15.

2. van der Woude LH, Hendrich KM, Veeger HE, et al. Manual wheelchair propulsion: effects of power output on physiology and technique. Med Sci Sports Exerc 1988;20:70-8.

3. Janssen TW, van Oers CA, van der Woude LH, Hollander AP. Physical strain in daily life of wheelchair users with spinal cord injuries. Med Sci Sports Exerc 1994;26:661-70.

4. Noreau L, Shephard RJ. Spinal cord injury, exercise and quality of life. Sports Med 1995;20:226-50.

5. Bussmann JB, Stam HJ. Techniques for measurement and assessment of mobility in rehabilitation: a theoretical approach. Clin Rehabil 1998;12:455-64.

6. Graves DE, Frankiewicz RG, Carter RE. Gain in functional ability during medical rehabilitation as related to rehabilitation process indices and neurologic measures. Arch Phys Med Rehabil 1999; 80:1464-70.

7. Noreau L. Relationship of impairment and functional ability to habitual activity and fitness following spinal cord injury. Int $\mathrm{J}$ Rehabil Res 1993;16:265-75.

8. Hall KM, Cohen ME, Wright J, Call M, Werner P. Characteristics of the Functional Independence Measure in traumatic spinal cord injury. Arch Phys Med Rehabil 1999;80:1471-6.

9. Bolin I, Bodin P, Kreuter M. Sitting position-posture and performance in C5-C6 tetraplegia. Spinal Cord 2000;38:425-34.

10. Harvey LA, Batty J, Fahey A. Reliability of a tool for assessing mobility in wheelchair-dependent paraplegics. Spinal Cord 1998; 36:427-31

11. Ota T, Akaboshi K, Nagata M, et al. Functional assessment of patients with spinal cord injury: measured by the motor score and the Functional Independence Measure. Spinal Cord 1996;34: 531-5.

12. Taricco M, Apolone G, Colombo C, Filardo G, Telaro E, Liberati A. Functional status in patients with spinal cord injury: a new standardized measurement scale. Arch Phys Med Rehabil 2000; $81: 1173-80$

13. Catz A, Itzkovich M, Agranov E, Ring H, Tamir A. SCIM-spinal cord independence measure: a new disability scale for patients with spinal cord lesions. Spinal Cord 1997;35:850-6.

14. Dallmeijer AJ, van der Woude LH, Hollander AP, van As $\mathrm{HH}$ Physical performance during rehabilitation in persons with spinal cord injuries. Med Sci Sports Exerc 1999;31:1330-5.

15. Janssen TW, van Oers CA, Veeger HE, Hollander AP, van der Woude LH, Rozendal RH. Relationship between physical strain 
during standardised ADL tasks and physical capacity in men with spinal cord injuries. Paraplegia 1994;32:844-59.

16. Michels KJ, Meijs PJ, Pons C. Bepaling van rolstoelgebonden functionaliteit tijdens het revalidatieproces. Ned Tijdschr Geneeskd 1993;137:1029-30.

17. Nijhoff TA, Hollander AP, Dallmeijer AJ, Hofman JW. The relation between heart rate and oxygen uptake during non-steady state arm exercise. In: van der Woude LH, Hopman MT, van Kemenade CH, editors. Biomechanical aspects of manual wheelchair propulsion. The state of the art II. Amsterdam: IOS Pr; 1999. p 16-25.

18. Mattison PG, Hunter J, Spence S. Development of a realistic method to assess wheelchair propulsion by disabled people. Int $\mathbf{J}$ Rehabil Res 1989;12:137-45.

19. Meijs PJ, Michels KJ, van der Woude LH, Veenbaas R, Rozendal RH. Technical requirements of wheelchair exercise testing in rehabilitation field research. In: van der Woude LH, Meijs PJ, van der Grinten BA, De Boer YA, editors. Ergonomics of manual wheelchair propulsion. Amsterdam: IOS Pr; 1993. p 61-70.

20. Cardus D, McTaggart WG, Ribas-Cardus F, Donovan WH. Energy requirements of gamefield exercises designed for wheelchairbound persons. Arch Phys Med Rehabil 1989;70:124-7.
21. Rankin G, Stokes M. Reliability of assessment tools in rehabilitation: an illustration of appropriate statistical analyses. Clin Rehabil 1998;12:187-99.

22. Nichols DP. Choosing an intraclass correlation coefficient. SPSS Keywords 1998;67. Available at: http://www.spss.com/tech/stat/ articles/whichicc.txt. Accessed May 13, 2002.

23. Janssen TW, van Oers CA, van der Woude LH, Hollander AP. Reliability of heart rate responses to non-steady-state activities of daily living in men with spinal cord injuries. Scand J Rehabil Med 1994;26:71-8.

24. Bhambhani YN, Eriksson P, Steadward RD. Reliability of peak physiological responses during wheelchair ergometry in persons with spinal cord injury. Arch Phys Med Rehabil 1991;72:559-62.

25. Janssen TW, van Oers CA, Rozendaal EP, Willemsen EM, Hollander AP, van der Woude LH. Changes in physical strain and physical capacity in men with spinal cord injuries. Med Sci Sports Exerc 1996;28:551-9.

\section{Suppliers}

a. Vantage NV, Polar Electro Oy, Professorintie 5, FIN-90440 Kempele, Finland.

b. Treadmill Giant; Bonte Zwolle BV, PO Box 281, 8000 AG Zwolle, The Netherlands. 